\title{
Phase, Compositional, and Morphological Changes of Human Dentin after Nd:YAG Laser Treatment
}

\author{
Chun-Pin Lin, DDS, MS, PhD, Bor-Shiunn Lee, DDS, MS, Feng-Huei Lin, PhD, Sang-Heng Kok, DDS, and \\ Wan-Hong Lan, DDS, DDsc
}

Although techniques for repairing root fracture have been proposed, the prognosis is generally poor. If the fusion of a root fracture by laser is possible, it will offer an alternative to extraction. Our group has attempted to use lasers to fuse a low melting-point bioactive glass to fractured dentin. This report is focused on the phase, compositional, and morphological changes observed by means of X-ray diffractometer, Fourier transforming infrared spectroscopy, and scanning electron microscopy-energy dispersive $X$-ray spectroscopy in human dentin after exposure to Nd:YAG laser. The irradiation energies were from $150 \mathrm{~mJ} /$ pulse-10 pps-4 s to $150 \mathrm{~mJ} /$ pulse-30 pps-4 s. After exposure to Nd:YAG laser, dentin showed four peaks on the X-ray diffractometer that corresponding to $\alpha$-tricalcium phosphate (TCP) and $\beta$-TCP at $2 \theta=30.78$ degrees $/ 34.21$ degrees and 32.47 degrees $/ 33.05$ degrees, respectively. The peaks of $\alpha$-TCP and $\beta$-TCP gradually increased in intensity with the elevation of irradiation energy. In Fourier transforming infrared analysis, two absorption bands at $2200 \mathrm{~cm}^{-1}$ and $2015 \mathrm{~cm}^{-1}$ could be traced on dentin treated by Nd:YAG laser with the irradiation energies beyond $150 \mathrm{~mJ} /$ pulse-10 pps-4 s. The energy dispersive $X$-ray results showed that the calcium/phosphorus ratios of the irradiated area proportionally increased with the elevation of irradiation energy. The laser energies of $150 \mathrm{~mJ} /$ pulse-30 pps-4 s and $150 \mathrm{~mJ} /$ pulse-20 pps-4 s could result in the $\alpha$-TCP formation and collagen breakdown. However, the formation of glass-like melted substances without $\alpha$-TCP at the irradiated site was induced by the energy output of $150 \mathrm{~mJ} /$ pulse-10 pps-4 s. Scanning electron micrographs also revealed that the laser energy of $150 \mathrm{~mJ} /$ pulse-10 pps-4 s was sufficient to prompt melting and recrystallization of dentin crystals without cracking. Therefore, we suggest that the irradiation energy of Nd:YAG laser used to fuse a low melting-point bioactive glass to dentin is $150 \mathrm{~mJ} /$ pulse-10 pps-4 s.

It has been $>30 \mathrm{yr}$ since lasers were first used in dentistry. Despite substantial development in this field in the United States, only Er:YAG laser has been granted marketing permission for use on dental hard tissues. The responses of soft tissues to lasers of different wavelengths are fairly well known, but the reactions of hard tissues are just being understood. Nd:YAG laser has long been investigated for its application in dental treatment. Previous studies suggested that Nd:YAG laser may function as an alternative or adjunctive therapy in the treatment of periodontally diseased root surfaces (1), endodontically infected teeth (2), incipient dental caries (3), and dentin hypersensitivity (4-6). Arakawa et al. (7) induced root fractures, irradiated them by Nd:YAG laser with air/water surface cooling, and then filled the fractures with a paste of tricalcium phosphate (TCP). Levy and Koubi (8) tested the permeability of a cracked root after crack lines had been filled with a TCP melted by a Nd:YAG laser. However, the decomposition temperature for pure apatite has been reported to be up to $1500^{\circ} \mathrm{C}$ (9), at which damage including multiple cracks of dentin may occur.

The effect of lasers on dentin is caused mainly by the changes in temperature that can be extremely high at the irradiated spot even for a short action time. Consequently, the dentin melts, vaporizes, and a crater is formed at the irradiation site. Laser energy causes a quick local temperature rise and prompts melting, recrystallization, and decomposition of the apatite crystals. Heat conduction should lead to a thermal equalization between the pronouncedly heated components and the surrounding tissues when a laser pulse of the order of a few microseconds is used.

The phase transformation and structural changes of the enamel at different temperature intervals have been investigated (10). However, similar changes in the dentin are less well known. According to the study of Kantola (11), recrystallization of the dentin occurred during $\mathrm{CO}_{2}$ laser irradiation. Simultaneously, growth in the crystal size was observed, and dentin of a low order of crystallinity changed structurally in such a way that it came to closely resemble the crystalline structure of the hydroxyapatite of normal enamel. Similar results were obtained with Nd:YAG laser that produced significant recrystallization and grain growth of the 
apatite, without the formation of second phases such as $\beta$-TCP (12).

We have tried to use laser energy to fuse a low melting point bioactive glass to the dentin. The dicalcium phosphate (DP)-bioactive glass with a low melting temperature has been reported to have a good mechanical strength and biocompatibility $(13,14)$. The present report is focused on the changes of human dentin after medium energy density Nd:YAG laser treatment. The examination was 3-fold: (a) using X-ray diffractometer (XRD) to characterize the phase changes; (b) using Fourier transforming infrared (FTIR) spectroscopy to trace the changes in functional groups; and (c) using scanning electron microscopy-energy dispersive X-ray (SEM-EDX) spectroscopy to examine the surface topography and calcium/phosphorus $(\mathrm{Ca} / \mathrm{P})$ molar ratios. Such collaborative data are fundamental to our understanding of the effects of Nd:YAG laser on the dentin, as well as determination of the appropriate laser energy for the treatment of root fracture.

\section{MATERIALS AND METHODS}

\section{Preparation of Specimens}

Extracted human molars were used in this study. Crowns with caries, restoration, and fractures were excluded. The remaining soft tissue was removed from the tooth surface with a dental scaler (Sonicflex 2000, KaVo Co., Biberbach, Germany). All teeth were then stored in $4^{\circ} \mathrm{C}$ distilled water containing $0.2 \%$ thymol to inhibit microbial growth until use.

The crown was amputated at the cementoenamel junction from each tooth by means of a slow-speed saw (Isomet; $10.2 \mathrm{~cm} \times 0.3$ $\mathrm{mm}$, arbor size $1 / 2$ inch, series $15 \mathrm{HC}$ diamond; Buehler Ltd., Lake Bluff, IL). A coronal root dentin disc with the thickness of $3 \mathrm{~mm}$ was cut fully hydrated perpendicular to the long axis of the root and was wet-polished to 600 grit (silicon carbide). The remaining fragments of dentin were pulverized into powder with an average particle size of $106 \mu \mathrm{m}$. The root dentin discs were prepared for SEM-EDX examination, whereas the dentin powder was prepared for FTIR and XRD analysis.

\section{Laser Treatment}

An Nd:YAG laser (SLT contact laser, DCL-8, Japan) that provided a constant beam of coherent, continuous monochromatic light with an emission wavelength of $1064 \mathrm{~nm}$ was used in this study. The specimens were randomly divided into four groups (A to D). In group A, B, and C, the pulse energy was $150 \mathrm{~mJ} /$ pulse for $4 \mathrm{~s}$ with the pulse frequencies as follows: A, $30 \mathrm{pps}$; B, $20 \mathrm{pps}$; and C, 10 pps. Group D received no laser treatment and served as a control. The laser was delivered through a SLT $400-\mu \mathrm{m}$ optic bare fiber with straight handpiece, and the tip was $2 \mathrm{~mm}$ from the target surface. The Nd:YAG laser was calibrated before use. Energy densities were measured as follows: group A, $2487 \mathrm{~J} / \mathrm{cm}^{2}$; group B, $1658 \mathrm{~J} / \mathrm{cm}^{2}$; and group C, $829 \mathrm{~J} / \mathrm{cm}^{2}$. Before irradiation, the specimen of powder form was condensed into a disc ( $3 \mathrm{~mm}$ in diameter and $1 \mathrm{~mm}$ in thickness) with a hydraulic force of $50 \mathrm{~kg} / \mathrm{cm}^{2}$ to prevent the powder from rising up or fluttering during laser beam sputtering on the powder.

\section{Analysis of the Specimens}

\section{XRD}

The crystalline phases of the dentin before and after laser irradiation were determined by a Rigaku X-ray powder diffractometer (Rigaka Denki Co., Ltd., Tokyo, Japan) with $\mathrm{CuK} \alpha$ radiation and $\mathrm{Ni}$ filter. The scanning range was 10 degrees to 60 degrees, with a scanning speed of 4 degrees $/ \mathrm{min}$. To determine the contents of different phases, relative intensities of the characteristic peaks of each phase were used.

\section{FTIR}

The phase transformation after laser treatment was studied with FTIR spectroscopy. FTIR spectra were recorded using KBr pellets ( $1 \mathrm{mg}$ sample per $300 \mathrm{mg} \mathrm{KBr}$ ) on a Jasco FTIR grating instrument (FTIR-300E, Jasco International Co., Ltd., Tokyo, Japan) with slow scan and normal slit width. The wavelength used was in the range of $4000-400 \mathrm{~cm}^{-1}$ to evaluate the functional groups in the specimens.

\section{SEM-EDX}

Morphology and microstructure of the specimens were observed under a scanning electron microscope. After laser treatment, specimens were immersed in $2.5 \%$ cold glutaraldehyde in $0.1 \mathrm{~mol} / \mathrm{L}$ cacodylate buffer at $\mathrm{pH} 7.4$ for $8 \mathrm{~h}$. All specimens were then serially dehydrated in graded ethanol solutions $(50 \%, 60 \%, 70 \%$, $80 \%, 90 \%, 95 \%$, and $100 \%$ ethanol) at 45 -min intervals, mounted on aluminum stubs, and sputter-coated with carbon. Specimens were then observed under a Philips 515 (Mohawk, NJ) SEM and analyzed by an energy-dispersive X-ray spectroscope (EDAX, PV9900, NJ). Both calcium and phosphorus were analyzed across the laser-irradiated area. Electron beams maintained at $2 \times 10-10$ amp were used and X-ray intensities in counts per second were recorded. The accelerating voltage was $15 \mathrm{kV}$.

\section{RESULTS}

\section{XRD Analysis}

Figure $1 a$ shows the X-ray diffraction patterns of nonirradiated powdered dentin. When compared with the standard JCPD card the peaks were all identified as nonstoichiometric hydroxyapatite structure. After Nd:YAG laser treatment, sharper peaks on the $\mathrm{X}$-ray diffraction pattern were noted as illustrated in Fig. 1, $b-d$. There were four peaks belonging to $\alpha$-TCP and $\beta$-TCP at $2 \theta=$ 30.78 degrees/34.21 degrees and 32.47 degrees/33.05 degrees, respectively, as shown in Fig. $1, c$ and $d$. The peaks corresponding to $\alpha$-TCP and $\beta$-TCP gradually increased in intensity with the elevation of irradiation energy. Other crystalline phases of calcium phosphate were not detected in the patterns.

\section{FTIR Analysis}

Figure 2 shows the FTIR patterns of dentin before and after Nd:YAG laser irradiation. The orthophosphate bands at 1030$1160 \mathrm{~cm}^{-1}$, and $600-560 \mathrm{~cm}^{-1}$, and the carbonate band at 870 


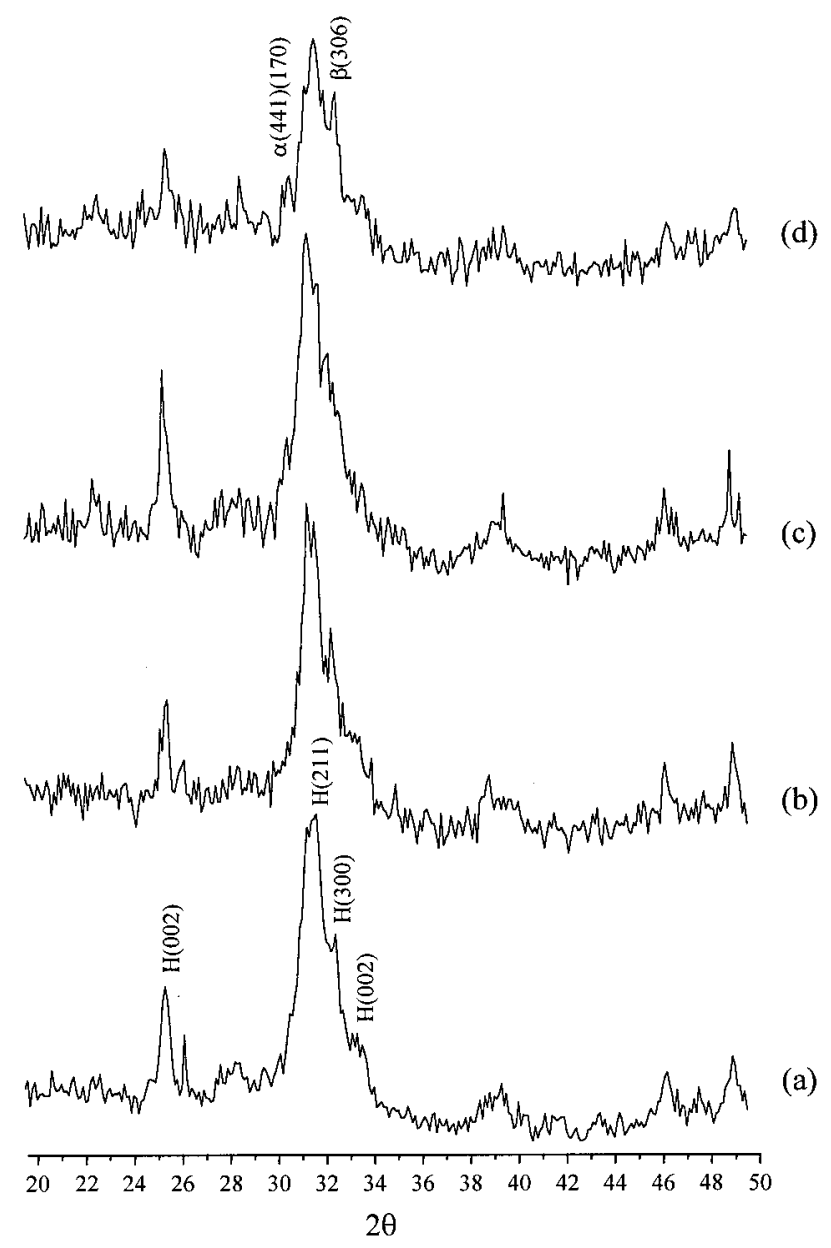

FIG 1. X-ray diffraction patterns of (a) powdered dentin without laser irradiation; and powdered dentin after Nd:YAG laser treatment with the energy output of $(b) 150 \mathrm{~mJ}-10$ pps-4 s; (c) $150 \mathrm{~mJ}-20 \mathrm{pps}-4 \mathrm{~s}$; and (d) $150 \mathrm{~mJ}-30$ pps-4 s. $H=$ hydroxyapatite; $\alpha=\alpha$-TCP; $\beta=$ $\beta$-TCP; $\theta=$ the angular locations of both X-ray source and counterrelative to the specimen surface; $2 \theta=$ diffraction angle.

$\mathrm{cm}^{-1}$ corresponded to the mineral phase of dentin. The most intense bands associated with $\mathrm{PO}_{4}^{-3}$ vibrations in calcium phosphate were the antisymmetric stretching mode at $1100-1000 \mathrm{~cm}^{-1}$ $\left(\nu_{2}\right.$ band) and antisymmetric bending mode at $600-550 \mathrm{~cm}^{-1}\left(\nu_{4}\right.$ band). The band at $1133 \mathrm{~cm}^{-1}$ was the vibrating mode of $\mathrm{HPO}_{4}^{-2}$ and that at $634 \mathrm{~cm}^{-1}$ corresponded to $\mathrm{OH}^{-}$. The carbonate band at $1450-1425 \mathrm{~cm}^{-1}$ was overlapped with the amide II band (1550 $\mathrm{cm}^{-1}, \mathrm{~N}-\mathrm{H}$ and $\left.\mathrm{C}-\mathrm{N}\right)$ and $\mathrm{OH}^{-}\left(1630 \mathrm{~cm}^{-1}\right)$. After laser treatment, two absorption bands at $2200 \mathrm{~cm}^{-1}$ and $2015 \mathrm{~cm}^{-1}$ appeared on the spectrum that suggested that a reaction had occurred in the organic matrix or between the organic matrix and minerals.

\section{SEM-EDX Analysis}

The dentin surface after laser treatment was substantially different in appearance when compared with the control. Large amounts of debris obscuring the tubule openings and constituting a smear layer were noted on the untreated dentin surface. After Nd:YAG laser treatment, modification of the dentin surface was observed in all specimens, but the degree of modification differed from one energy
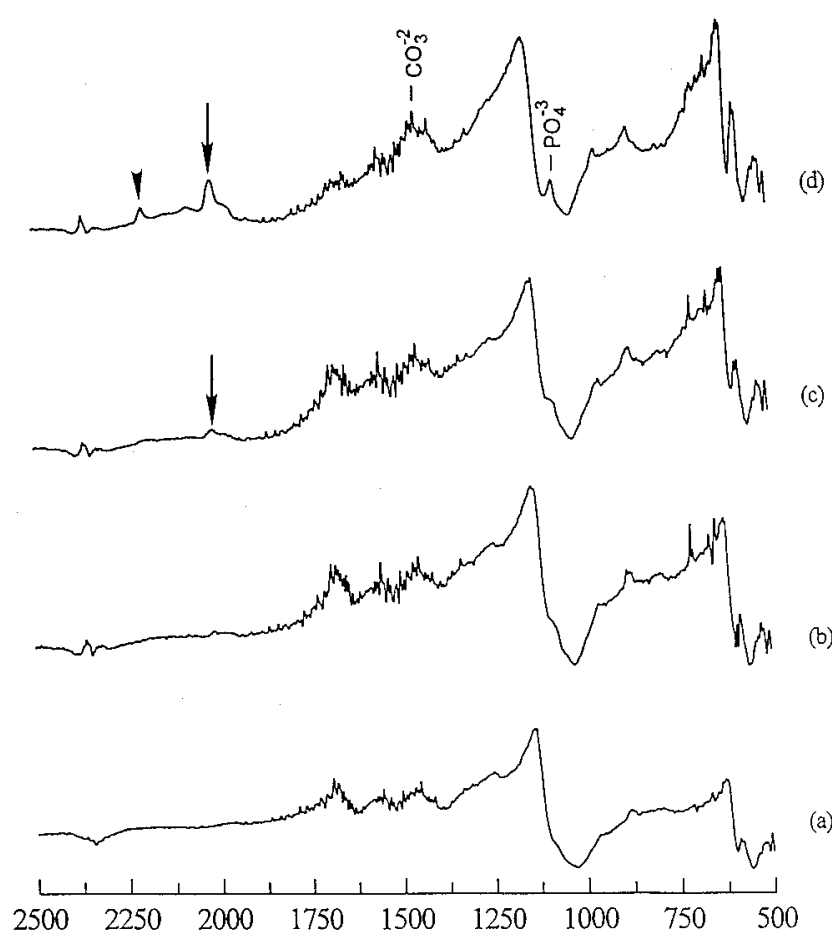

Wave Length $\left(\mathrm{cm}^{-1}\right)$

FIG 2. FTIR spectra of (a) dentin without Nd:YAG laser treatment and dentin after Nd:YAG laser treatment with the energy outputs of $(b)$ $150 \mathrm{~mJ}-10$ pps-4 s, (c) $150 \mathrm{~mJ}-20$ pps-4 s, (d) $150 \mathrm{~mJ}-30 \mathrm{pps}-4 \mathrm{~s}$. The weak-to-medium absorption band at $2015 \mathrm{~cm}^{-1}$ (arrows) was very characteristic of the primary amine salt. The $\mathrm{P}-\mathrm{H}$ bond at 2200 $\mathrm{cm}^{-1}$ (arrowhead) was due to the reaction of HAP crystal with organic matrix at the extremely high temperature.

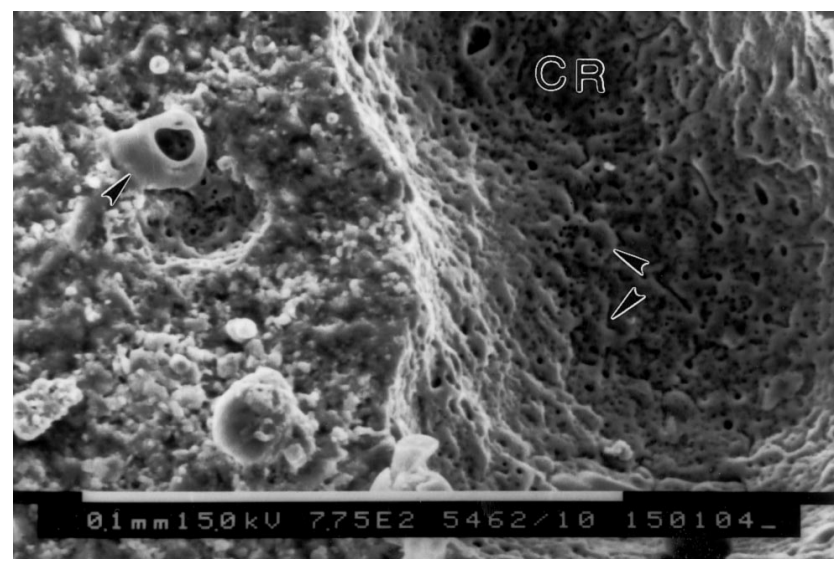

FIG 3. Photomicrograph of the dentin surface after Nd:YAG laser treatment of $150 \mathrm{~mJ}-10 \mathrm{pps}-4 \mathrm{~s}$. There is a shallow crater on the surface. Inside and around the crater, globules (arrowheads) probably composed of melted hydroxyapatite were found. $C R=$ crater. Bar $=0.1 \mathrm{~mm}$.

level to another. Figure 3 shows an irradiated crater on the dentin surface after Nd:YAG laser treatment of $150 \mathrm{~mJ} /$ pulse-10 pps-4 s. Inside and around the crater, globules probably composed of melted hydroxyapatite were found. The $\mathrm{Ca} / \mathrm{P}$ ratios at the center of the crater, margin of the crater, and peripheral nonirradiated site were 1.464, 1.427 , and 1.398 , respectively. The lased appearance of dentin after 


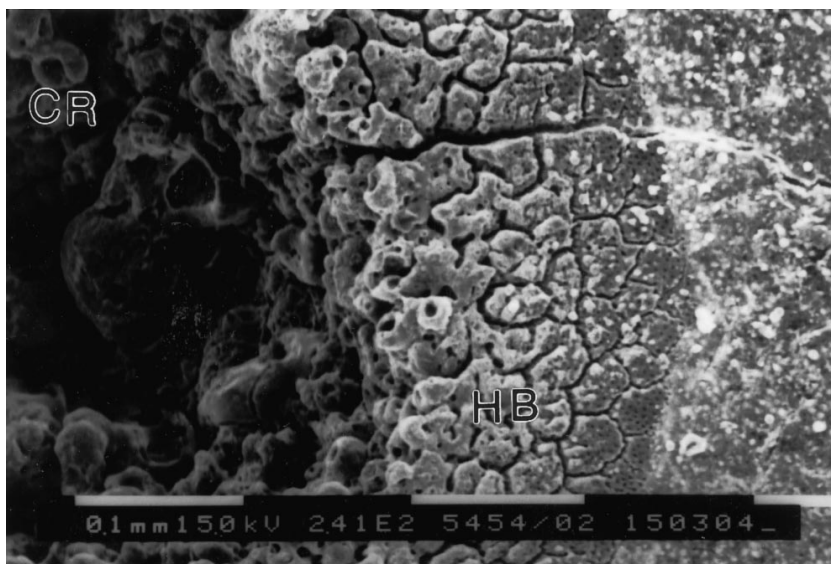

FIG 4. Photomicrograph of the dentin surface after Nd:YAG laser treatment of $150 \mathrm{~mJ}-30 \mathrm{pps}-4 \mathrm{~s}$. There is a deep crater with cracks and heat-induced band around the crater. $C R=$ crater; $H B=$ heat-induced band; $b a r=0.1 \mathrm{~mm}$.

TABLE 1. Results of X-ray quantitative analysis of dentin before and after laser irradiation

\begin{tabular}{clc}
\hline \multicolumn{1}{c}{ Energy Output } & \multicolumn{1}{c}{ Areas Examined } & $\begin{array}{c}\text { Ca/P } \\
\text { Ratios }\end{array}$ \\
\hline $150 \mathrm{~mJ} /$ pulse-10 pps-4 s & $\begin{array}{l}\text { Center of the crater } \\
\text { Margin of the crater }\end{array}$ & 1.464 \\
& Peripheral nonirradiated site & 1.427 \\
& & \\
& & 2.398 \\
$150 \mathrm{~mJ} /$ pulse-20 pps-4 s & Inner side of the crater & 1.599 \\
& Margin of the crater & 1.59 \\
& Peripheral nonirradiated site & 1.431 \\
& & \\
$150 \mathrm{~mJ} /$ pulse-30 pps-4 s & Inner side of the crater & 2.250 \\
& Center of the band & 1.679 \\
& Peripheral nonirradiated site & 1.420 \\
\hline & &
\end{tabular}

$\mathrm{Nd}$ :YAG laser treatment of $150 \mathrm{~mJ} / \mathrm{pulse}-20 \mathrm{pps}-4 \mathrm{~s}$ was similar to that in Fig. 3, except that several cracks radiated from the crater. The $\mathrm{Ca} / \mathrm{P}$ ratios at the inner of the crater, margin of the crater, and peripheral nonirradiated site were $2.122,1.599$, and 1.431 , respectively. Figure 4 reveals a deep crater with cracks on the dentin surface after Nd:YAG laser treatment of $150 \mathrm{~mJ} /$ pulse-30 pps-4 s. The crater with cracks was formed by the rapid evaporation of water and decomposition of organic constituents. In addition a heat-induced band could be found around the crater. The $\mathrm{Ca} / \mathrm{P}$ ratios at the inner of the crater, center of the band, and peripheral nonirradiated site were 2.250, 1.679 , and 1.420 , respectively. These EDX data are summarized in Table 1.

\section{DISCUSSION}

The responses of tissues to lasers are influenced by the irradiation parameters (i.e., the wavelength, repetition rate, pulse energy, and optical properties of the tissue). The ultimate effect of laser irradiation depends on the distribution of energy inside the tissue. The process of heat conduction influences the rise in temperature at different distances from the irradiated site. Although dentin can partially disperse the irradiation energy of Nd:YAG laser, it will eventually be heated to the point of charring or melting provided that the energy source is high enough.
In this study, it was evident that Nd:YAG laser irradiation could cause the dentin to melt and recrystallize. From the center of the crater to the peripheral nonirradiated area a gradient of temperature was found. The phase, compositional, and morphological changes of dentin were influenced by this gradient profile. The high energy of Nd:YAG laser, such as $150 \mathrm{~mJ} /$ pulse-30 pps-4 s and 150 $\mathrm{mJ} /$ pulse-20 pps-4 s could cause the hydroxyapatite (HAP) of dentin to melt partially and decompose into calcium oxide or amorphous calcium phosphate. The cooling rate of HAP after irradiation could be very rapid and thus led to the formation of noncrystalline or metastable crystalline products such as $\alpha$-TCP and $\beta$-TCP $(15,16)$. This was in agreement with the XRD results.

It has been reported that, as the temperature increases, a series of reactions in the dentin may happen as follows (17):

$$
\begin{array}{ll}
2 \mathrm{HPO}_{4}{ }^{-4} \rightarrow \mathrm{P}_{2} \mathrm{O}_{7}{ }^{-4}+\mathrm{H}_{2} \mathrm{O} & \left(250^{\circ}-550^{\circ} \mathrm{C}\right) \\
\mathrm{P}_{2} \mathrm{O}_{7}^{-4}+2 \mathrm{OH}^{-} \rightarrow 2 \mathrm{PO}_{4}^{-3}+\mathrm{H}_{2} \mathrm{O} & \left(550^{\circ}-700^{\circ} \mathrm{C}\right) \\
\beta-\mathrm{Ca}_{3}\left(\mathrm{PO}_{4}\right)_{2} \rightarrow \alpha-\mathrm{Ca}_{3}\left(\mathrm{PO}_{4}\right)_{2} & \left(1125^{\circ} \mathrm{C}\right) \\
\mathrm{Ca}_{3}\left(\mathrm{PO}_{4}\right)_{6}(\mathrm{OH})_{2} \rightarrow 2 \alpha-\mathrm{Ca}_{3}\left(\mathrm{PO}_{4}\right)_{2} & \\
\quad+\mathrm{Ca}_{4} \mathrm{P}_{2} \mathrm{O}_{9}+\mathrm{H}_{2} \mathrm{O} & \left(1300^{\circ} \mathrm{C}\right) .
\end{array}
$$

As predicted by the reaction, $\beta$-TCP will be formed in the dentin once the temperature is higher than $700^{\circ} \mathrm{C}$ and $\alpha$-TCP will be formed above $1125^{\circ} \mathrm{C}$. In this study, we could not identify the characteristic peaks of tetracalcium phosphate monoxide $\left(\mathrm{Ca}_{4}\left(\mathrm{PO}_{4}\right)_{2} \mathrm{O}\right)$ and $\mathrm{CaO}$ on the XRD patterns. We believe that TTCP and $\mathrm{CaO}$ could transform to other forms of calcium phosphates such as $\alpha$-TCP or $\beta$-TCP during cooling. This indicates that Nd:YAG laser irradiation of $150 \mathrm{~mJ} /$ pulse- $30 \mathrm{pps}-4 \mathrm{~s}$ and 150 $\mathrm{mJ} / \mathrm{pulse}-20 \mathrm{pps}-4 \mathrm{~s}$ can result in a temperature rise of more than $1125^{\circ} \mathrm{C}$ on the dentin surface. Such temperature could result in the breakdown of organic materials in addition to the changes in inorganic phase. Changes of organic substances could be traced from our FTIR absorption bands at $2200 \mathrm{~cm}^{-1}$ and $2015 \mathrm{~cm}^{-1}$. The weak to medium absorption band at $2015 \mathrm{~cm}^{-1}$ was very characteristic of the primary amine salt. The $\mathrm{P}-\mathrm{H}$ bond at 2200 $\mathrm{cm}^{-1}$ was due to the reaction of HAP crystal with organic matrix at the extremely high temperature. Spencer et al. (18) tentatively assigned these two bands to cyanate and cyanamide.

In this study, we used EDX for qualitative chemical analysis with the help of standard specimens. A calibration curve of $\mathrm{Ca} / \mathrm{P}$ ratio was used with four standard specimens of tetracalciunm phosphate $(\mathrm{Ca} / \mathrm{P}=2)$, hydroxyapatite $(\mathrm{Ca} / \mathrm{P}=1.67)$, TCP $(\mathrm{Ca} / \mathrm{P}$ $=1.5)$, and calcium pyrophosphate $(\mathrm{Ca} / \mathrm{P}=1)$. The $\mathrm{Ca} / \mathrm{P}$ ratios of the four standards were analyzed by EDX with comparison of the intensity of $\mathrm{Ca}$ and $\mathrm{P}$ characteristic peaks. The calibration curve was drawn by $\mathrm{Ca} / \mathrm{P}$ ratio versus $\mathrm{Ca}$ peak intensity/P peak intensity ratio. The $\mathrm{Ca} / \mathrm{P}$ ratios of the dentin with or without laser treatment were measured by an extrapolation method.

The molar ratios of calcium to phosphorus in nonirradiated dentin were $1.398,1.431$, and 1.420 (Table 1) instead of 1.67 because dentin is a nonstoichiometric calcium-deficient hydroxyapatite: $\mathrm{Ca}_{10-\mathrm{X}}\left(\mathrm{HPO}_{4}\right)_{\mathrm{X}}\left(\mathrm{PO}_{4}\right)_{6-\mathrm{X}}(\mathrm{OH})_{2-\mathrm{X}}(0<\times<2)$. The $\mathrm{Ca} / \mathrm{P}$ molar ratios increased with the elevation of irradiation energy. At the same time the ratios decreased from the center of the crater to the peripheral nonirradiated area. Some phosphorous ions may evaporate because phosphorous is easy to volatilize once the temperature is up to $1125^{\circ} \mathrm{C}$. Phosphorous evaporation is one of the major reasons leading to the increase of $\mathrm{Ca} / \mathrm{P}$ ratio when dentin is treated with Nd:YAG laser. This phenomenon also happened after 
$\mathrm{CO}_{2}$ laser irradiation (19). In this occasion the molar ratios of $\mathrm{Ca} / \mathrm{P}$ were even higher than two at the inner side of the crater. We did not detect the center of the crater because the crater was so deep that the electrons could not escape from it. Thus the signal from the center of the crater was obscure. However, we believe that similar changes occurred in the inner of the crater.

It has been reported that $\alpha$-TCP has greater solubility and degradability than HAP in an aqueous environment (20); thus the formation of $\alpha$-TCP will decrease the chemical stability. The results of this study indicate that the formation of primary amine salt and $\mathrm{P}-\mathrm{H}$ bonds by the energy outputs of $150 \mathrm{~mJ} /$ pulse- 30 pps-4 s and $150 \mathrm{~mJ} /$ pulse-20 pps-4 s could result in $\alpha$-TCP formation and collagen breakdown. However, the formation of glasslike melted substances without $\alpha$-TCP at the irradiated site could be induced by the energy output of $150 \mathrm{~mJ} /$ pulse- $10 \mathrm{pps}-4 \mathrm{~s}$. SEM micrographs also revealed that the laser energy of $150 \mathrm{~mJ} / \mathrm{pulse}-10$ pps-4 s was sufficient to prompt melting and recrystallization of dentin crystals without cracking. Therefore, we suggest that the irradiation energy of Nd:YAG laser used to fuse a low meltingpoint bioactive glass to dentin is $150 \mathrm{~mJ} / \mathrm{pulse}-10 \mathrm{pps}-4 \mathrm{~s}$.

This study was supported by a grant (NSC-88-2314-B-002-026) from the National Science Council of Taiwan, Republic of China.

Dr. C.-P. Lin is chairman and associate professor, Dr. Lee is a PhD graduate student, and Dr. Lan is associate dean and professor, Department of Endodontics, School of Dentistry, National Taiwan University, Taipei, Taiwan, Republic of China. Dr. Kok is lecturer, Department of Maxillofacial Surgery, School of Dentistry, National Taiwan University, Taipei, Taiwan, Republic of China. Dr. F.-H. Lin is professor, Institute of Biomedical Engineering, College of Medicine, National Taiwan University, Taipei, Taiwan, Republic of China. Address requests for reprints to Dr. Wan-Hong Lan, Department of Endodontics, School of Dentistry, National Taiwan University, No. 1, Chang Te Street, Taipei, Taiwan, Republic of China.

\section{References}

1. Dunlap J. Is there a laser in your future? Dent Econ 1988;78:40-4.

2. Gutknecht N, Kaiser F, Hassan A, Lampert F. Long-term clinical eval- uation of endodontically treated teeth by Nd:YAG lasers. J Clin Laser Med Surg 1996;14:7-11.

3. Myers TD, Myers WD. The use of a laser for debridement of incipient caries. J Prosthet Dent 1985;53:776-9.

4. Lan WH, Liu HC. Sealing of human dentinal tubules by Nd:YAG laser. J Clin Laser Med Surg 1995;13:329-33.

5. Lan WH, Liu HC. Treatment of dentin hypersensitivity by Nd:YAG laser. $\mathrm{J}$ Clin Laser Med Surg 1996;14:89-92.

6. Liu HC, Lin CP, Lan WH. Sealing depth of Nd:YAG laser on human dentinal tubules. J Endodon 1997;23:691-3.

7. Arakawa S, Killoy WJ, Spencer P. Treatment of root fracture by $\mathrm{CO}_{2}$ and Nd:YAG lasers-An in vitro study. J Endodon 1996;22:662-7.

8. Levy GC, Koubi GF. An experimental technique to repair cracked teeth using calcium phosphate, melted by a laser beam: an in vitro evaluation Compend Contin Educ Dent 1993;11:1444-52.

9. Brown WE, Smith JP, Lehr JR, Frazier AW. Crystallographic and chemical reactions between octacalcium phosphate and hydroxyapatite. Nature 1962;196:1050-5.

10. Kuroda S, Flower BO. Compositional, structural and phase changes in in vitro laser irradiated human tooth enamel. Calcif Tissue Int 1984;36:361-9

11. Kantola S. Laser-induced effects on tooth structure. VII. X-ray diffraction study of dentin exposed to a $\mathrm{CO}_{2}$ laser. Acta Odontol Scand 1973;31: $381-6$.

12. Kinney JH, Haupt DL, Balooch M, White JM, Bell WL, Marshall SJ Marshall GW Jr. The threshold effects of $\mathrm{Nd}$ and $\mathrm{Ho}$ :YAG laser-induced surface modification on demineralization of dentin surfaces. J Dent Res 1996; 75:1388-95

13. Lin FH, Liao CJ, Liu HC, Chen KS, Sun JS. Behavior of fetal rat osteoblasts cultured in vitro on the DP-bioactive glass substratum. Mater Chem Phys 1997;49:270-6.

14. Lin CP, Lin FH, Tseng YC, Kok SH, Lan WH, Liao JD. Treatment of tooth fracture by medium energy $\mathrm{CO}_{2}$ laser DP-bioactive glass paste: compositional, structural, and phase changes of DP-bioglass paste after irradiation by $\mathrm{CO}_{2}$ laser. Biomaterials 2000;21:637-43.

15. Zyman Z, Weng J, Liu X, Li X, Zhang X. Phase and structural changes in hydroxyapatite coating under heat treatment. Biomaterials 1994;15:151-5

16. Gross KA, Berndt CC. Thermal processing of hydroxyapatite for coating production. J Biomed Mater Res 1998;39:580-7.

17. Locardi B, Pazzaglia UE, Gabbi C, Profilo B. Thermal behavior of hydroxyapatite for medical applications. Biomaterials 1993;14:437-41.

18. Spencer $\mathrm{P}$, Cobb CM, McCollum MH, Wieliczka DM. The effects of $\mathrm{CO}_{2}$ laser and Nd:YAG with and without water/air surface cooling on tooth root structure: correlation between FTIR spectroscopy and histology. J Periodontol Res 1996;31:453-62.

19. Takahashi K, Kimura Y, Matsumoto K. Morphological and atomic analytical changes after $\mathrm{CO}_{2}$ laser irradiation emitted at 9.3 microns on human dental hard tissues. J Clin Laser Med Surg 1998;16:167-73.

20. Radin SR, Ducheyne P. The effect of calcium phosphate ceramic composition and structure on in vitro behavior. I. Dissolution. J Biomed Mater Res 1993;27:25-34. 